\title{
Positive and negative effects facing university education by allowing foreign universities to invest and open branches in KSA - Vision 2030 (Case Study Arab East Colleges \& Qassim University)
}

\author{
Hoda Ahmed Ibraheem Abdelnabi \\ Arab East Collages, Kingdom of Saudi Arabia \\ Sally Elawady \\ College of Business\& Economic, Qassim University, Kingdom of Saudi Arabia
}

\begin{abstract}
Keywords
University education sector - investment in education - foreign universities - private universities challenges facing university education.
\end{abstract}

\begin{abstract}
The aim of the study is to shed light on the negative and positive effects facing university education as a result of allowing foreign universities to open branches in KSA - Vision 2030, which represents a challenge for the private and governmental university education sector. Hence the main research question arises, "What are the effects of encouraging investment by foreign universities in the Kingdom on local universities in Saudi Arabia?" .

Design/methodology/approach: - The study used the descriptive-analytical method, and questionnaires were distributed to the community sample of employees of the Eastern Colleges of Graduate Studies and the Qaseem University the researchers used E-view program for analysis.

Findings:- The study reached several results, most important among which are the positive effects of allowing foreign universities to open branches in the Kingdom of Saudi Arabia, achieving a qualitative shift in the path of Saudi universities on the basis of empowerment, excellence, quality, and contributing to the development of the educational and research process, raising the efficiency of the Saudi university education system and raising the efficiency of Expenditure, the development of financial resources for universities, and human capabilities, the presence of negative effects of students 'orientation to foreign universities and their reluctance to enter local universities, researchers recommend the allocation of a budget-oriented interested in the innovation, creativity, and scientific research. Activating the partnership between ministry of labor, higher education, and vocational training institutions. Encouraging the private sector to invest in technical education. following developed teaching strategies that focus on innovation and creativity for the future generations industry and the encouraging of new investments directed to scientific research in line with (Saudi Vision 2030).
\end{abstract}

\section{Introduction}

The path to success, survival and competitiveness in this changing world done through the preparation of an educated, conscious generation that believes in its role and the causes of its nation. Therefore, Opening and dealing with other civilizations has become an inescapable matter, and there is no point in intellectual and cultural closure, something that requires higher education universities and institutes to define mechanisms for dealing with challenges through a new vision that is consistent with the changes and the role expected of them.

\section{Research problem}

The Vision KSA 2030 came in support of investment in private university education as well as allowing the opening of foreign universities branches and investment within the Kingdom in the university education sector, which represents a threat to the private. and governmental university education sector. so came the main question for research "What are the positive and negative effects of encouraging investment to enter universities Foreign in the Kingdom of Saudi Arabia to local universities. In addition to the following sub-questions: 
What are the motives for allowing entry to foreign universities in the Kingdom of Saudi Arabia?

What is the role of the private university education sector in raising the efficiency of the university education system - Vision 2030?

What is the role of the private university education sector while allowing entry to foreign universities?

What is the role of the university education sector in light of the standard of competition between local and private universities and foreign universities?

What are the economic challenges that will face local university education if foreign universities are allowed to enter?

\section{The hypothesis of the study:}

Based on the theoretical analysis presented here, the following hypotheses can be adopted

H1. Allow foreign universities to open branches in KSA has a positive impact on local universities in terms of raising the efficiency of the university education system.

H2. Allow foreign universities to open branches in KSA has a negative impact on local universities in terms of the 'increasing number of student registrations to foreign universities.

H3. Allow foreign universities to open branches in KSA has a negative impact on College graduates in terms of decline productivity in the many fields.

H4. Encouraging legislation and laws in Saudi Arabia, foreign universities to invest in technical education.

\section{The Theoretical Study}

Investing in education

Facing the rapid changes in the patterns of development and the culture of investment in education has taken place in our country with the hasty trend towards private university education. As for the West, this trend is still practiced with great caution and caution. Because private universities usually funded by investors are driven by a rapid profit incentive, not the incentive for scientific and academic development. Even universities with a respected academic level in the United States are still confined to public or private universities funded by not-for-profit NGOs, and not from investment companies. In the Arab world, we see that the element of financial investment is behind most, new private universities so that, the licenses of these universities are granted to commercial companies, whose purposes are to seek more investment and more profits.

\section{Justifications for interest in investing in education.}

The interest in education economics, especially in the last three decades of the last century, has increased significantly, and this interest is due to:

1 - Education is a capital commodity that contributes to reducing the number of workers, as it is known that the productivity of the educated person is more than the productivity of the uneducated worker, and education for society as a whole is a repository of intangible money that is more than the capital that is more than the most important capital.

2- Investment in education is highly beneficial, as it is a special branch of human investment, as well as the cost in this type of investment, can produce high benefits, and also that educated individuals, and then to society As a whole, these benefits are represented in the form of higher rewards and increased productivity, as well as better leadership in society.

3- Education has gained significant financial allocations both in the developing countries and the developed countries, despite the limited economic resources of the developing countries).

The methods used to the total quality management for investment in education

1. Strategy: It is for the senior leadership to have a development plan for the future of the institution in the next (3-5) years, and training is the most appropriate solution for the institution for that.

2. Structure: This means the restoration of a new system for improving education outputs and increases the effectiveness of education operations while adding new innovations and creativity that contribute to improving the education system's effectiveness.

3. Staff: It means treating workers appropriately and satisfying their needs through the use of the human relations method at work. 
4. Skills: It means improving human capabilities and competencies through innovation and creativity continuous training in order to devise new competitive methods of education.

5. Shared values: It means creating a new education strategy organizational culture, identifying prevailing values and replacing them with a protective culture that is appropriate for continuous development in education.

\section{International experiences in investing in private university education}

It is noticeable that the liberalization of trade in education services in general, and higher education in particular, reap the benefits mainly of countries exporting these services, such as the United States, Britain, Canada, and Australia. It has become rare for a university in such countries to have no educational or research activity that extends across international borders. They are competing to provide human capital in order to obtain what is called the Knowledge-based Economy necessary to support the rapid growth in the knowledge-based economy and the urgent need for these countries to obtain large numbers of highly qualified people with distinct capabilities in specific disciplines. Also, previous experiences have shown that the government sector is not the only source of funding for higher education, as the private sector, local community donations, aid, and partnerships with the industrial sector play an important role in financing higher education

\section{Contemporary challenges facing universities:}

- The absence of competition in the global markets for graduates of national universities.

- A decline in productivity in the many fields of graduates of national universities.

- The lack of national companies 'share in the global market due to the human resources resulting from the current university education patterns.

- Increased unemployment among graduates from national universities.

- Increasing the supply of university graduates from the demand for them.

\section{Literature}

Patrinos, (2018), Strong link between education and earnings, in the latter half of the 20th century that the link between education and earnings was established in theory and practice. The importance of the earnings benefit of schooling is vital for a variety of social issues. These include economic and social policy, racial and ethnic discrimination, gender discrimination, income distribution, and the determinants of the demand for education. This link between education and earnings is formally made in the calculation of the rate of return to investment in education.

Almankash \& Aniq, (2017), their study tries to identify the status of the private sector investment in specialized academic programs at higher educational institutions in the Kingdom of Saudi Arabia. Furthermore, the research addressed some of the countries' experiences related to investing in specialized academic programs by private sector in order to develop a suggested model for investing in specialized academic programs by private the researchers adopted the descriptive method. The research results revealed a weakness in the participation of funding the academic programs in higher educational institutions by the private sector. Moreover, the results pinpointed there are many obstacles that hinder investment in specialized academic programs. The research portrayed the profitable means that assisted in forming the suggested model and recommended that the higher educational institutions in the Kingdom of Saudi Arabia should keep pace with the requirements of the labor market on assigning the specialized academic programs, which encourage the private sector to invest.

Alshibany \& Zabon, (2017), investment in education, No one disagrees that the oriented investments in education is the Pillar and the target of development and the pivot of human development, human of wealth is the first and the last important pillar to achieve an accelerated rate for the overall development of the country. The option of investing in human resource, must be a strategic choice in Iraq if we want to keep up with what the global economic developments and the pursuit of the technological revolution and take advantage of the informatics environment data. The investment in education is the most important source of promoting human development because the education is the key to the knowledge and development of communities through the development a real of human capital. In order to clarify this study were to search the importance of human development and the role of who's played, and to clarify the importance of investment in education as an important source of income. 
Salman, (2017), Investment in higher education and its relationship with the impact on the labor market / applied research in Iraqi private colleges Investing in higher education effected on the most important factors of production which the return an individual and social than economic returns found by searching the growing problem of unemployment, especially among the youth graduates, where the unemployment rate in 2010 (\%50) of these high rates have led to increased migration of scientific minds graduate recently, to search for job opportunities outside of Iraq for not hiring functions and this is in vainclearin the human and financial resources lead to structural imbalances in the Iraqi economy . When calculating the correlation coefficient between the graduates and the unemployment rate where it reached (0.21) emerged from the results of the analysis that the more the number of students enrolled and graduates of whom the greater rates of unemployment in Iraq, especially "in the terms of humanitarian and administrative, should the permission of the alignment between undergraduate majors and needs of the labor market, while encouraging private sector investment in the field of technical education to achieve a balance between the numbers of graduates and their terms of reference and the labor market.

Sergio, (2015), Higher education is more popular than ever in Latin America and the Caribbean (LAC), where gross enrolment rates have risen dramatically - from 17\% in 1991 to $43 \%$ in 2012, according to World Bank estimates. In Colombia, the rate increases closely paralleled that of the region, but in Chile, the increase was even more remarkable: from $21 \%$ to $71 \%$. This turnaround reflected not only greater private investments in education, but also public policies aimed at boosting access, including greater financial support for students (Chile) and a geographical expansion of higher education institutions (Colombia). In the process, the mix of students in these institutions for both countries became much more inclusive - in other words, higher education is no longer just for the children of high-income families. the study result indicates that suggests that investing in higher education isn't always profitable.

Shrin, (2012), Higher Education Investing brains between reality and expectations. The study aimed to shed light on investment in higher education, and the study reached investment in education that differs from investment in material capital, that there is a relationship between investment in the human element in terms of time and quality, and the return from this investment, and the study recommended the need to invest in science, As a culture of the present and the future, and invest in culture as the science of a comprehensive future.

Dahan, (2010), Educational investment in human capital, the aim of This research is to study the relationship between education and human capital, and to analyze the resources for financing educational investments and their trends, together with the role of human capital (accumulated by the educational investment) in economic growth, All this in a theoretical framework and empirical case for Algeria.

Goodman (2011) The study aimed to clarify the great role that the new partnership between industries and universities plays in diversifying the higher education sector, and the extent of transformation of public universities in Japan that have less than $20 \%$ of students in higher education, while getting $80 \%$ of the education budget. National Higher Education into independent bodies, the Japanese generally understood the value and importance of personal investment in higher education. The results concluded that the shift from the funding pattern based on the tradition of universities to a pattern of financing based on competition, led to the flow of more funds from government institutions and the industrial sector to a few universities interested in research.

Gharby, (2008), investment in education and Theory, this research focused on the analysis and study of the relationship between education, and economic system and the various schools of intellectual considered the relationship between education and economic development, in addition to the need for human resource development and how to extract revenue in investment education.

Marsikova, (2005), investigate the possibilities of investing in human capital in the financial market of the Czech Republic. In particular, the conditions for this investment would be different among individuals due to the difference of bequest amount and the credit market condition in financing the money for human capital investment or education. There is also a higher risk for possible investors in determining individuals' income and adverse selection. they use expected returns to education of the Czech higher education students as a benchmark for creating student loans and human capital contracts models. The financial market and institutions should offer different ways of financial assistance. However, the financial market of the Czech Republic is not prepared for this type of investment 
Almalky, (2003), The economic return on investment in university education in the Kingdom of Saudi Arabia, the study's objective is to measure the rate of economic returns for investing on university education in the Kingdom of Saudi Arabia. By utilizing the Internal Rate of Returns (IRR) method of estimation, the study found that the rate at the individual level is $(6.67 \%)$ and at the social level is $(2.77 \%)$. These results imply that investing on university education in the Kingdom of Saudi Arabia is economically feasible at the individual level, but not at the social level; that is due to high costs borne by the state in providing such service and to economic waste associated with it.

\section{Summary of Literature}

- Through listing previous studies, we note that studies that support the importance of investing in education also confirm some reservations and warning as:

- The necessity of linking higher education with the industrial sector and creating new investments directed to scientific research, which will lead to more funds flowing from government institutions and the industrial sector to universities interested in research.

- To achieve the public interest, the rights of members of society, and taking into account the interests of workers, the state must remain a partner in the ownership of the projects to be allocated.

- The necessity of working on implementing reforms in the ways of financing higher education by rationalizing expenditures and developing legislation related to society's contribution to bearing part of the costs of higher education through the trend towards private education.

- The lack of foundations and standards according to which private universities are classified, the low level of graduates of some colleges, the suffering of some practical colleges due to the lack of numbers of scientific and technical cadres, and the decrease in the total of the general secondary grades, which leads to student registration in private universities.

All previous studies discussed the importance of investing in education and the negative effects, but this is the first study that discussed the Positive and negative effects facing university education by allowing foreign universities to invest and open branches in KSA, Vision 2030.

\section{Methodology}

The study used the descriptive analytical approach, to measure Negative and positive effects facing university education by allowing foreign universities to open branches in KSA, Through the use of questionnaire, analyzed by the E-view program.

That was designed to scan this effect and analyze its data, to measure the economic challenges that will face local university education if foreign universities are allowed to enter.

\section{The study samples}

"The basic principle in scientific research is that it should be done on all members of the research community because this called for the validity of the results, but to choose a sample from them if this is not possible due to the large number of them, (Al-Assaf, 2003, p. 96). So, we chose the sample study consist of Arab East Collages \& Qassim University in KSA. We distributed a questionnaire and we obtain 405 responses.

\section{Study Tool}

This section includes an explanation and a description of the study and investigation of its validity and consistency. It also includes an explanation of the statistical methods used in the study, we used a questionnaire, it includes 27 questions divided into two parts:

A: The first part of the questionnaire was designed to identify the characteristics of the sample and determine the extent of its impact on the results of the study.

B: Design of the second part of the questionnaire to include some paragraphs related to the study axes, and the questions were divided into three main axes:

- The first axis: Negative and positive effects facing university education by allowing foreign universities to open branches in KSA.

- The second axis: What are the motives for allowing entry to foreign universities in the Kingdom of Saudi Arabia. 
- Third axis: the economic challenges that will face local university education if foreign universities are allowed to enter in KSA.

\section{Content Validity}

First: Test Validity: To identify the validity of the study in measuring what was put to measure was presented to (3) members of the faculty of Arab East Collages also, Economics and Management - Qassim University, to know the extent of compatibility with the objectives of the study and the questions that try to answer them and in the light of their opinions It was agreed to finalize the study tool.

Second: Internal consistency: After verifying the Test Validity of the study, it was applied in the field and the calculation of the correlation coefficient for the internal truth of the questionnaire, where the correlation coefficient was calculated between the degrees of all the terms of the questionnaire.

Internal consistency for the first level: There is a Negative and positive effects facing university education by allowing foreign universities to open branches in KSA. Table (1) Correlation coefficients between the degrees of each of the first axis statements from the overall degree of the axis.

\begin{tabular}{|l|l|l|l|}
\hline First Axis Phrases & Correlation Coefficient & First Axis Phrases & Correlation Coefficient \\
\hline 1 & 0.651 & 6 & 0.821 \\
\hline 2 & 0.815 & 7 & 0.755 \\
\hline 3 & 0.741 & 8 & 0.531 \\
\hline 4 & 0.616 & 9 & 0.879 \\
\hline 5 & 0.671 & 10 & 0.891 \\
\hline
\end{tabular}

Source: Based on questionnaire, 2019-2020.

Internal consistency for the second level: There are the motives for allowing entry to foreign universities in the Kingdom of Saudi Arabia.Table (2) Correlation coefficients between the degrees of each of the second axis statements from the overall degree of the axis.

\begin{tabular}{|l|l|l|l|}
\hline Second Axis Phrases & Correlation Coefficient & Second Axis Phrases & Correlation Coefficient \\
\hline 1 & 0.622 & 5 & 0.675 \\
\hline 2 & 0.741 & 6 & 0.877 \\
\hline 3 & 0.832 & 7 & 0.825 \\
\hline 4 & 0.894 & 8 & 0.678 \\
\hline
\end{tabular}

Source: Based on questionnaire, 2019-2020.

Internal consistency for The Third level: There is an economic challenges that will face local university education if foreign universities are allowed to enter.Table (3) Correlation coefficients between the degrees of each of the Third axis statements from the overall degree of the axis.

\begin{tabular}{|l|l|l|l|}
\hline Third Axis Phrases & Correlation Coefficient & Third Axis Phrases & Correlation Coefficient \\
\hline 1 & 0.891 & 6 & 0.815 \\
\hline 2 & 0.785 & 7 & 0.737 \\
\hline 3 & 0.681 & 8 & 0.797 \\
\hline 4 & 0.755 & 9 & 0.896 \\
\hline \multicolumn{1}{|c|}{0.811} & \multicolumn{2}{l}{} \\
\hline
\end{tabular}

Source: Based on questionnaire, 2019-2020.

It is clear from Table (1), (2), (3) that the values of the correlation coefficients between the degree of all the terms and the total score of the identification axes all take positive values, with statistical significance at a mean level (0.01), which means a high degree of internal consistency and correlation Reflects a high degree of honesty for the scale paragraphs.

Third: Reliability: to measure the stability of the study instrument, we use the (Cronbach's alpha coefficient a), where stability is intended to give the same results if repeated use. (Wathen, 2013). Table (4) Values of the Cronbach's alpha coefficients. 


\begin{tabular}{|l|l|l|l|}
\hline & Questionnaire axes & $\begin{array}{l}\text { Number of } \\
\text { paragraphs }\end{array}$ & $\begin{array}{l}\text { Cronbach's } \\
\text { alpha }\end{array}$ \\
\hline Level 1 & $\begin{array}{l}\text { There are a positive and negative effects facing university education } \\
\text { by allowing foreign universities to open branches in KSA }\end{array}$ & 10 & 0.812 \\
\hline Level 2 & $\begin{array}{l}\text { There are the motives for allowing entry to foreign universities in the } \\
\text { Kingdom of Saudi Arabia. }\end{array}$ & 8 & 0.755 \\
\hline Level 3 & $\begin{array}{l}\text { There is an economic challenge that will face local university } \\
\text { education if foreign universities are allowed to enter. }\end{array}$ & 0.835 \\
\hline & Reliability & 27 & 0.814 \\
\hline
\end{tabular}

Source: Based on questionnaire, 2019-2020.

It is clear from Table (4) that the coefficient of persistence of the a Cronbach's alpha coefficient was about $0.812,0.755,0.835$, respectively. $(0.814)$, all of which have high stability values, indicating that the questionnaire has a high degree of stability, and therefore can be relied upon in the field application of the study.

\section{Statistical methods used in the study}

Statistical methods used in the study included 3 axes: -

The first axis: Negative and positive effects facing university education by allowing foreign universities to open branches in KSA, ten questions were allocated to cover the issues of this axis. The results of the analysis shown in Table (5):

1.The existence of sufficient knowledge of the role of branches foreign universities shows that $43.4 \%$ do not have a great deal of knowledge of the role of the branch's foreign universities, while $24.2 \%$ have a weak knowledge. The results of the five-digit Likert scale in this evaluation indicated that it scored 3.45 (medium) with a standard deviation of 1.12, While $31.4 \%$ had sufficient knowledge of the importance of the role of the branches foreign universities. The results of the five- level Likert scale in this evaluation indicated that it obtained 3.27 (medium) with a standard deviation of 1.14.

2.For the university's contribution of the achieving a qualitative shift in the path of Saudi universities on the basis of empowerment, excellence, the results of the study showed that $33.8 \%$ believe that the university does not have a contribution in the empowerment, while $29 \%$ of the sample believes that this contribution is weak. The evaluation obtained 2.52 (medium) with a standard deviation of 1.02.

3.The effective contributions to the development of the educational and quality, results showed that $95.1 \%$ of the sample, believe that it is Strong, with an average capacity of 4.2 from the Likert scale (Strong) with a standard deviation of 1.01. For the role of the effective contributions to the development of the research process, $20.8 \%$ believe it to be medium, $16.2 \%$ think it is weak, and the Rijkaard score averaged 2.14 with a standard deviation of 1.004 . Results showed that $20.5 \%$ of the research sample had weak information about the effective contributing about branches foreign universities with a weighted average of the Likert scale (0.9) with a standard deviation of 0.025 .

4.As for the negative effects, there is a preference for the Saudi student to go towards foreign universities in the Kingdom, the results of the study showed that $88.1 \%$ believe that foreign universities are attractive to Saudi students, With a standard deviation of 0.321 , also There is a preference among students in the countries neighboring Saudi Arabia to go towards foreign universities in the of Saudi Arabia. the study showed that $64.2 \%$ believe that foreign universities are attractive to students in the countries neighboring Saudi Arabia, With a standard deviation of 0.681 
Table 5: Negative and positive effects facing university education by allowing foreign universities to open branches in KSA

\begin{tabular}{|l|l|l|}
\hline first axis Questions & Average & $\begin{array}{l}\text { standard } \\
\text { deviation }\end{array}$ \\
\hline The existence of sufficient knowledge of the role of branches foreign universities. & 0.43 & 1.12 \\
\hline sufficient knowledge of the importance of the role of the branch's foreign universities. & 0.31 & 1.14 \\
\hline $\begin{array}{l}\text { university's contribution of the achieving a qualitative shift in the path of Saudi } \\
\text { universities on the basis of empowerment }\end{array}$ & 0.33 & 1.02 \\
\hline $\begin{array}{l}\text { university's contribution of the achieving a qualitative shift in the path of Saudi } \\
\text { universities on the basis of excellence }\end{array}$ & 0.34 & 1.02 \\
\hline The effective contributions to the development of the educational. & 0.95 & 1.01 \\
\hline The effective contributions to the development of the quality. & 0.94 & 1.00 \\
\hline the role of the effective contributions to the development of the research process. & 0.21 & 1.004 \\
\hline The information about the effective contributing about branches foreign universities. & 0.21 & 0.025 \\
\hline $\begin{array}{l}\text { there is a preference for the Saudi student to go towards foreign universities in the } \\
\text { Kingdom }\end{array}$ & 0.88 & 0.321 \\
\hline $\begin{array}{l}\text { There is a preference among students in the countries neighboring Saudi Arabia to go } \\
\text { towards foreign universities in the of Saudi Arabia. }\end{array}$ & 0.64 & 0.681 \\
\hline \multicolumn{2}{|l|}{ Source Based } & \\
\hline
\end{tabular}

Source: Based on questionnaire, 2019.

The second axis: What are the motives for allowing entry to foreign universities in Saudi Arabia. Eight questions were allocated to analyze the problems and obstacles faced. Table (6) shows that the most important motives faced by foreign universities in the Kingdom of Saudi Arabia.

1.For the economic motivation to allow the entry of foreign universities in the Saudi Arabia., the results of the study showed that $75.1 \%$ believe that the university does have a contribution in the empowerment, with a standard deviation of 0.361 ,also For the social motivation to allow the entry of foreign universities in the Saudi Arabia., the results of the study showed that $77 \%$ believe that the university does have a contribution in the empowerment, with a standard deviation of .0424 .

2.Results showed that $80.5 \%$ of the research sample shows that the branches foreign universities necessary to raising the efficiency of the Saudi university education system with a weighted average of the Likert scale (2.8) with a standard deviation of 1.095

$3.67 \%$ of the sample respondents believe that the branches foreign universities have weakly contribution to the development of financial resources for universities with a standard deviation of 1.15

4.As for the emergence of new investments directed to scientific research in line with (Saudi Vision 2030), $98 \%$ of the respondents saw this as strong, and the Likert score was at an average of 4.1 with a standard deviation of 1.21 , and $89 \%$ saw its necessary to develop human capabilities. The Likert scale achieved an average score of 3.9 and a standard deviation of 1.08

$5.65 \%$ believe that Public and private universities support the idea of setting up branches of foreign universities in Saudi Arabia, with a standard deviation of .0821,also 61\% believe that Public and private universities find that the idea of setting up branches of foreign universities in Saudi Arabia raises the quality of education outcomes with a standard deviation of .0 .824 .

Table 6: the motives for allowing entry to foreign universities in Saudi Arabia

\begin{tabular}{|l|l|l|}
\hline Second axis Questions & Average & $\begin{array}{l}\text { Sta. } \\
\text { deviation }\end{array}$ \\
\hline $\begin{array}{l}\text { There is an economic motivation to allow the entry of foreign universities in the Saudi } \\
\text { Arabia. }\end{array}$ & 0.75 & 0.361 \\
\hline $\begin{array}{l}\text { There is a social motivation to allow the entry of foreign universities in the Saudi Arabia. } \\
0.77\end{array}$ & 0.424 \\
\hline $\begin{array}{l}\text { the branches foreign universities necessary to raising the efficiency of the Saudi } \\
\text { university education system. }\end{array}$ & 0.81 & 1.095 \\
\hline $\begin{array}{l}\text { the branches foreign universities have contribution to the development of financial } \\
\text { resources for universities. }\end{array}$ & 0.67 & 1.151 \\
\hline
\end{tabular}




\begin{tabular}{|l|l|l|}
\hline $\begin{array}{l}\text { Allowing entry to foreign universities in Saudi Arabia is working on the emergence of } \\
\text { new investments directed to scientific research in line with (Saudi Vision 2030). }\end{array}$ & 0.98 & 1.21 \\
\hline $\begin{array}{l}\text { Allowing entry to foreign universities in Saudi Arabia is necessary to develop human } \\
\text { capabilities. }\end{array}$ & 0.89 & 1.08 \\
\hline $\begin{array}{l}\text { Public and private universities support the idea of setting up branches of foreign } \\
\text { universities in Saudi Arabia }\end{array}$ & 0.65 & 0.821 \\
\hline $\begin{array}{l}\text { Public and private universities find that the idea of setting up branches of foreign } \\
\text { universities in Saudi Arabia raises the quality of education outcomes }\end{array}$ & 0.61 & 0.824 \\
\hline
\end{tabular}

Source: Based on questionnaire, 2019.

The Third axis: Challenges facing university education by allowing foreign universities to open branches in Saudi Arabia.

- The number of nine questions was allocated to analyze the economic challenges that will face local university education if foreign universities are allowed to enter in KSA, Table 7 shows that:

1.There is a positive impact on local universities in terms of raising the efficiency of the university education system when opening new branches for foreign universities in the KSA., the results of the study showed that $75 \%$ believe that there is a positive impact on local universities when opening new branches for foreign universities in KSA, with a standard deviation of 0.341 , also For the social motivation to allow the entry of foreign universities in the Saudi Arabia., the results of the study showed that $67 \%$ believe that the branches for foreign universities does have a contribution in the Social and cultural development, with a standard deviation of 0.514 .

2.There is a negative impact on College graduates in terms of decline productivity in the many fields when opening new branches for foreign universities in KSA., the results of the study showed that $55 \%$ believe that there is a positive impact on local universities when opening new branches for foreign universities in KSA, with a standard deviation of 2.01

$3.75 \%$ of the sample respondents believe that There is a positive impact on local universities and facing economic challenges in higher education if foreign universities are allowed to open branches in the Kingdom of Saudi Arabia, with a standard deviation of 0.515 . And $90 \%$ of the sample find that the most important economic challenges facing local universities, is the high cost of the university education service and also the low return on investment in the university education sector, with a standard deviation of 0.522

$4.89 \%$ of the sample respondents believe that Local universities ready to compete with foreign universities inside the kingdom with a standard deviation of 0.341.also believe that opened the branches foreign universities necessary Raising the quality of Saudi university education and comparing it with international learning, the results of the study showed that $91 \%$ believe that its necessary Raising the quality of Saudi university education and comparing it with international learning, with a standard deviation of 0.398

5.For the economic challenges facing private and public university education when opening branches of foreign universities in the of Saudi Arabia., the results of the study showed that $85.1 \%$ believe that the university does have a contribution in the empowerment, with a standard deviation of .0161,also For the social challenges facing private and public university education when opening branches of foreign universities in the of Saudi Arabia., the results of the study showed that $87 \%$ believe that the university does have a contribution in the empowerment, with a standard deviation of 0.512 .

Table 7: the economic challenges that will face local university education if foreign universities are allowed to open branches in Saudi Arabia.

\begin{tabular}{|l|l|l|}
\hline Third axis Questions & Average & $\begin{array}{l}\text { standard } \\
\text { deviation }\end{array}$ \\
\hline $\begin{array}{l}\text { There is a positive impact on local universities in terms of raising the efficiency of the } \\
\text { university education system when opening new branches for foreign universities. }\end{array}$ & 0.75 & 0.341 \\
\hline $\begin{array}{l}\text { the branches for foreign universities do have a contribution in the Social and cultural } \\
\text { development, }\end{array}$ & 0.67 & 0.514 \\
\hline $\begin{array}{l}\text { There is a negative impact on College graduates in terms of decline productivity in the } \\
\text { many fields when opening new branches for foreign universities in KSA }\end{array}$ & 0.55 & 2.01 \\
\hline
\end{tabular}




\begin{tabular}{|l|l|l|}
\hline $\begin{array}{l}\text { There is a positive impact on local universities and facing economic challenges in } \\
\text { higher education if foreign universities are allowed to open branches in the Kingdom of } \\
\text { Saudi Arabia. }\end{array}$ & 0.75 & 0.515 \\
\hline $\begin{array}{l}\text { high cost of the university education service and also the low return on investment in } \\
\text { the university education sector is the most important economic challenges facing local } \\
\text { universities. }\end{array}$ & 0.90 & 0.522 \\
\hline $\begin{array}{l}\text { Local universities ready to compete with foreign universities inside the kingdom } \\
\text { Raising the quality of Saudi university education and comparing it with international } \\
\text { learning }\end{array}$ & 0.89 & 0.341 \\
\hline $\begin{array}{l}\text { Raising the quality of Saudi university education and comparing it with international } \\
\text { learning. }\end{array}$ & 0.91 & 0.398 \\
\hline $\begin{array}{l}\text { There are economic challenges facing private and public university education when } \\
\text { opening branches of foreign universities in the of Saudi Arabia }\end{array}$ & 0.85 & 0.161 \\
\hline $\begin{array}{l}\text { There are social challenges facing private and public university education when } \\
\text { opening branches of foreign universities in the of Saudi Arabia. }\end{array}$ & 0.87 & 0.512 \\
\hline
\end{tabular}

Source: Based on questionnaire, 2019.

\section{Conclusions}

Allowing foreign universities to open branches in the Kingdom of Saudi Arabia achieves a qualitative shift in the path of Saudi universities on the basis of:

- Empowerment, excellence, and quality contributing to the development of the educational and research process raising the efficiency of spending and developing the financial resources of universities and human capabilities, in line with (vision Saudi Arabia 2030), especially desire students and parents to obtain excellence education.

- This decision will help to establish a competition standard for local universities, which will increase competitiveness in raising the efficiency of the university education system.

- Increase competition between local universities to raise the efficiency of the university education system to reach international academic education level.

- Raising the efficiency of the development of human capabilities, creativity, innovation, financial resources, and expenditure, in Saudi universities.

- Diversity of different cultures inside the Kingdom

- higher education institutions face a threat through, desire students who will a registration in foreign universities.

- Simulating Saudi universities with foreign universities, which helps to raise the quality of learning outcomes.

- Reducing students' desire to travel abroad to join foreign universities

- Reducing the emigration of skilled human minds.

- It will also contribute to providing many options for students who don't want to travel abroad or cannot afford its costs.

- Moreover, this decision opens the door for many students in neighboring countries to move to Saudi Arabia in order to complete their education.

- Saudi Universities will seek to raise the development of Governance, quality education and, provision of services quality, equality, and alignment between education outcomes and labor market need.

\section{Recommendations}

- Saudi Universities must Create a new education strategy continuously depends on: - Governance, development, Innovation, Creativity, quality education and, provision of services quality, equality, and alignment between education outcomes and labor market needs.

- It is necessary to raise awareness of the importance of supporting new branches of foreign universities in the Kingdom of Saudi Arabia

- The necessity of enacting new legislation and laws that encouraging, motivation and facilitate work foreign universities to open branches to invest in technical education in the Kingdom of Saudi Arabia. 
- The establishment of a committee at the Ministry of Higher Education presenting all information about foreign universities.

- There is an urgent need to find some kind of contribution to continuous coordination and development between all local universities and foreign universities

- Improving human capabilities and competencies through innovation and creativity continuous training in order to devise new competitive methods of education.

- Creating a new education strategy organizational culture, identifying prevailing values and replacing them with a protective culture that is appropriate for continuous development in education.

\section{References}

Al-Assaf, S., (2003) Introduction to Research in Behavioral Sciences (Second Volume). Riyadh: Library Obeikan, P. 96.

Almankash, S., \& Aniq, A., (2017), the status of the private sector investment in specialized academic programs at higher educational institutions in the Kingdom of Saudi Arabia. Journal of the Faculty of Education, Al-Azhar University, Issue 174 July 2017.

Al-Tarturi, M., \& Jweihan, A., (2006), Total Quality Management in Higher Education Institutions, Libraries, and Information Centers, Al-Masirah House for Publishing, Distribution, and Printing Amman, p. 110.

Al-Zalzala, Y., (2015) The Concept of Investing in Higher Education, Finance and Economic Review, National Assembly, Kuwait, pp. 1, 2.

El-Dahshan, J., (2003) Readings in the economics of education, P., 14.

El-Helou, D., (2010), The Role of Financial Policies in Investing in Education, Master Thesis, University of Baghdad, College of Economics and Administration, Iraq, p. 130

Marsikova, K., (2005). Human Capital Investment in Higher Education: Empirical Evidence of Expected Earning in The Czech Republic. Technical University of Liberec, Faculty of Economics, Czech.

Nashwan, J., (2004), Developing competencies for academic supervisors in university education in light of the concept of total quality management, Quality Conference in Palestinian University Education, Al-Quds Open University, July, p., 9.

Wathen, S. A., (2013), Statistical analysis of management data, McGraw-Hill Education

https://www.worldcat.org/title/basic-statistics-for-business-economics/oclc/1110090886\&referer=brief results

https://blogs.worldbank.org/education/strong-link-between-education-and-earnings

https://www.iasj.net/iasj?func=fulltext\&aId=121753

http://al-dananeer.edu.iq/wp-content/uploads/2017/11/5

https://blogs.worldbank.org/jobs/higher-education-always-good-investment

http://alwaei.gov.kw/volumes/558/derasat/Pages/Education.aspx

https://bu.umc.edu.dz/theses/economie/ADAH3338.pdf

http://fll.univ-biskra.dz/images/pdf_revue/pdf_revue_02-03/gharbi\%20sabah.pdf

https://translate.google.com/\#view=home\&op=translate\&sl=ar\&tl=en\&tex

https://www.machro3.org/2018/11/investment-opportunities-in-education-sector.html 